\title{
Obstetric hysterectomy: a receding trend
}

\section{Fasiha Tasneem*, Vijayalakshmi Shanbhag}

Department of Obstetrics and Gynecology, Dr SCGMC, Nanded, Maharashtra, India

Received: 08 November 2018

Accepted: 06 December 2018

\section{*Correspondence:}

Dr. Fasiha Tasneem,

E-mail: fasihatasneem06@gmail.com

Copyright: (c) the author(s), publisher and licensee Medip Academy. This is an open-access article distributed under the terms of the Creative Commons Attribution Non-Commercial License, which permits unrestricted non-commercial use, distribution, and reproduction in any medium, provided the original work is properly cited.

\begin{abstract}
Over 500,000 women die each year due to complications of pregnancy and childbirth, a number that has remained relatively unchanged since 1990, when the first global estimates of the burden of maternal mortality were developed. Hemorrhage due to uterine atony, adherent placenta and PPH are still the causes of maternal death in developing countries. Although advances have been made in the development of conservative medical and surgical treatment of obstetric haemorrhage like brace sutures, internal iliac artery ligation, selective arterial embolization etc emergency obstetric hysterectomy remains a lifesaving procedure in the management of intractable haemorrhage unresponsive to conservative management.
\end{abstract}

Keywords: Adherent placenta, Brace sutures, Haemorrhage, Internal iliac artery ligation, Obstetric hysterectomy

\section{INTRODUCTION}

Emergency obstetric hysterectomy though a lifesaving surgical procedure but is considered as risky operation in modern obstetrics. Emergency obstetric hysterectomy $(\mathrm{EOH})$ is defined as extirpation of the uterus either at the time of cesarean section or following vaginal delivery, or within the puerperium period.

Over 500,000 women die each year due to complications of pregnancy and childbirth, a number that has remained relatively unchanged since 1990 , when the first global estimates of the burden of maternal mortality were developed. ${ }^{1}$ Hemorrhage due to uterine atony, adherent placenta and PPH are still the causes of maternal death in developing countries. ${ }^{2}$ Although advances have been made in the development of conservative medical and surgical treatment of obstetric haemorrhage, emergency peripartum hysterectomy remains a lifesaving procedure in the management of intractable haemorrhage unresponsive to conservative management. ${ }^{3}$ It is performed when all conservative measures have failed to achieve haemostasis, as a last resort to save a mother's life sacrificing the maternal reproductive capacity. With increase in the number of cesarean delivery; abnormal placental adhesions, placenta previa has emerged as the most common indication in developed countries.4In developing countries most common indications is postpartum hemorrhage when conservative measures fail and ruptured uterus when other measures to control bleeding fails. ${ }^{5}$ Obstetric hysterectomy is associated with increased risk of intra operative and post-operative maternal morbidity and mortality. ${ }^{6}$ The decision of obstetric hysterectomy particularly in the younger age group and low parity causes a great dilemma to the surgeon. Timely decision is crucial in preventing catastrophes.

\section{HISTORY}

Obstetric hysterectomy was originally devised more than 200 years ago as a surgical attempt to manage life threatening obstetric hemorrhage and infection. ${ }^{7}$ Eduardo Porro of Milan performed the first planned caesarean hysterectomy in which both the infant and the mother survived. He documented his operation in a paper published in 1876. Porro advocated hysterectomy 
combined with caesarean section to control post-partum haemorrhage and to prevent infection. The maternal death rate following the operation remained high but was substantly below the rate prior to the introduction of the procedure. The Porro procedure contributed to more favourable outcome for both the mother and the infant, having sterility and premature menopause as its side effects. ${ }^{8}$ Since Porro time many improvements have been introduced to the management, the most recent trend is towards fertility retaining approaches.

\section{Incidence of obstetric hysterectomy}

The incidence of obstetrical hysterectomy due to uterine atony is declining from $42 \%$ to $29 \%$. Use of uterotonic and haemostatic agents, surgical technique like internal iliac artery ligation had probably decreased incidence of obstetric hysterectomy due to uterine atony.

While the incidence due to abnormal placentation is increasing from $25 \%$ to $41 \% .^{9}$ In a study by Shirodker et al from 2008 to 2016 there were 45 cases of emergency hysterectomies amongst 28,207 deliveries during the period of study giving an incidence of $0.16 \% .^{10}$ In developed countries, the reported incidence of emergency hysterectomy is below $0.1 \%$ of the total normal deliveries performed, while in developing countries, the incidence rates are as high as 1-5/ 1000 of all the deliveries performed. ${ }^{2,11}$

\section{Indications of obstetric hysterectomy}

Cesarean hysterectomy may be classified as emergent, indicated non-emergent, and for elective sterilization. The classic historical indications for emergency cesarean hysterectomy are life-threatening hemorrhage and infection. The advent of broad-spectrum antibiotics, along with improved pharmaceutical therapy and procedures for controlling hemorrhage (e.g. embolization, B-Lynch suture), has resulted in a decline in the incidence of emergent cesarean hysterectomy. Uterine rupture and placenta accreta, particularly previa with accreta, have been encountered with increasing frequency in recent years as the number of cesarean sections and attempted vaginal deliveries after cesarean section increases. $^{12}$

Other indications for obstetric hysterectomy include Uterine rupture, Extension of uterine incision at caserean delivery, Cervical cancer, Ovarian cancer. Obstetric hysterectomy in the developed world is mainly done for gynaecological indications such as sterilisation and leiomyoma in obstetrical practice, but in developing countries it is usually done when conservative measures fail to control the haemorrhage. ${ }^{13}$

In a study by Bhattacharyya $\mathrm{R}$ et al Postpartum haemorrhage (PPH) (43.2\%), ruptured uterus (RU) (32\%) and morbidly adherent placenta (MAP) $(24.7 \%)$ were the three major indications for obstetric hysterectomy. ${ }^{14}$

\section{Obsteric hysterectomy for PPH}

Primary postpartum hemorrhage is the loss of more than $500 \mathrm{ml}$ of blood within the first twenty-four hours of delivery or loss of any amount that is enough to cause hemodynamic instability in the mother or loss of more than $10 \%$ of the total blood volume. Hemorrhage, usually occuring in the post- partum period, is responsible for between one quarter and one third of obstetric deaths. ${ }^{15}$ Hemorrhage continues to be the leading individual cause of maternal death worldwide accounting for $27.1 \%$ of deaths as recently as $2014 .{ }^{16}$ Cesarean hysterectomy still remains a necessary tool for the obstetrician. Knowledge of this operation and skill at its performance saves lives in catastrophic rupture of the uterus or intractable PPH. In a study by Nishupriya et al there were 24, 213 deliveries, and 16 obstetric hysterectomies, $56.25 \%$ of emergency hysterectomies were done for Atonic PPH followed by $31.25 \%$ for Rupture uterus. ${ }^{3}$ The $\mathrm{PPH}$ is the most common indication for obstetric hysterectomy in the study by Kant Anita et al and Dr. Raghunath Bhattacharyya et al. ${ }^{14,17}$

\section{Obstetric hysterectomy for morbidly adherent placenta}

A morbidly adherent placenta attaches itself deeply into the myometrium. The conditions include placenta accreta, increta or percreta and together constitute approximately 1 in 2,500 pregnancies. Placenta percreta constitutes about $5 \%$ of all cases of adherent placenta. This is usually diagnosed when usual placental separation is discovered to be absent. ${ }^{18}$ Morbid adherence of the placenta to the uterine wall is a potentially life-threatening obstetric complication that frequently requires interventions such as caesarean hysterectomy and high-volume blood transfusion. Morbidly adherent placentation may be suspected when there is a placenta praevia in a woman with a history of caesarean section or other uterine surgery. ${ }^{19}$ Morbidly adherent placenta was most common indication for obstetric hysterectomy the study conducted by Kastner et al, Praneshwari et al and Bhawna Sharma et al. ${ }^{7,20,21}$ In a study by Marwaha Parveen et al morbidly adherent placenta was the second most common indication in six $(20 \%)$ women. ${ }^{22}$

\section{Obstetric hysterectomy for uterine rupture}

The term rupture uterus is used to denote a breach in the continuation of a gravid uterine musculature from any cause after fetal viability. ${ }^{23}$ Uterine rupture is one of the serious complications encountered in obstetrics, threatening the pregnant women and her fetus; more so in the developing countries. In developing countries, the incidence is high due to a greater number of unbooked obstetric emergencies, often originating from rural areas with poor antenatal care.

In a study by Marwaha Parveen et al ,rupture uterus was the most common indication for cesarean hysterectomy seen in $18(60 \%)$ women, all of whom were referred from 
peripheral rural areas within a radius of 15 to $18 \mathrm{~km}$. Out of these 18 cases, seven had previous one cesarean section and were handled by dais with oxytocin abuse, five were in obstructed labor, and six had prolonged and intravenous oxytocin administration by the dai. There were three cases of bladder rupture among the 18 with rupture uterus and all the three had a scarred uterus. ${ }^{22}$ Ruptured uterus is the most common indication in the study by Shirodker S D et al accounting for $36.58 \%$ of cases. $^{10}$

\section{Surgical technique of obstetric hysterectomy}

Cesarean hysterectomy can be accomplished through most abdominal wall incisions. A vertical incision provides best exposure, but often when performed as an emergency a transverse incision has been used and may be adequate.

If required, division of rectus muscle with ligation of the inferior epigastric arteries (modified Maylard) is helpful.

The type of uterine incision used is guided by obstetric indications; however, a low vertical incision is less likely to extend and lacerate the uterine vasculature. In all stressful surgical situations, the technique with which the surgeon is most comfortable is appropriate.

As with many surgical emergencies, the decision to proceed to hysterectomy is often more important than the technique required. The hysterectomy is performed in the same manner as a routine abdominal hysterectomy.

\section{TYPE OF OBSTETRIC HYSTERECTOMY}

A study by Shirodker et al in $62 \%$ of the cases, subtotal hysterectomy was performed. It is not always possible to do total abdominal hysterectomy as the patients' general condition is often poor. It is important to ligate the stumps doubly and carefully, as tissues are more vascular and edematous. ${ }^{10}$ Majority in the study by Jayaram et al underwent total hysterectomy. $80.7 \%$ underwent total abdominal hysterectomy and $19.3 \%$ underwent subtotal abdominal hysterectomy. ${ }^{24}$

In the study by Ambika $\mathrm{H}$ E et al all the women who were taken up for surgery underwent subtotal hysterectomy since it is faster, technically less complicated and there is less risk of ureteric injury and in a haemodynamically unstable patient, subtotal hysterectomy requires less operative time and is associated with lesser blood loss. ${ }^{25}$ Clarke et al and Zorlu et al found that there is no difference in blood loss and operating time on comparing total hysterectomy with subtotal hysterectomy. ${ }^{9,26}$

\section{Complications of obstetric hysterectomy}

Maternal morbidity associated with cesarean hysterectomy may be as high as $56 \%$. In the study by
Jayaram et al the complications were Febrile morbidity (52.63\%) Wound infection, Urinary tract infection, Thrombophlebitis (24.6\%) Pneumonitis , Pneumothorax, ARDS, Post intubation laryngitis (14\%) DIC (3.5\%) Pressure sores $(3.5 \%)$ Vesicovaginal fistula (1.7\%) Acute tubular necrosis (1.7\%) Pelvic collection (1.7\%) Relaparotomy for bleeding (3.5\%) Mechanical ventilation $(24.6 \%)$ Myocardial ischaemia $(1.7 \%) .^{24}$

In a study by Bhat et al fever was the most common complication seen in (04) $26.6 \%$ cases. Other Postoperative complications were wound Infection in 02 $(13.3 \%)$ cases, septicemia in $02(13.3 \%)$ cases. One $(6.7 \%)$ patient had mortality due to septicemia. ${ }^{6}$ In a study by Mahbuba et al we found common complication of obstetric hysterectomy were operative hemorrhage $75 \%$, febrile morbity $25 \%$ and $12.5 \%$ was in shock as continuation of the poor preoperative condition, whereas hemorrhage was in $46.34 \%$, febrile illness in $70.73 \%$, shock in $22 \%$ in the study of Nazma Bano et al. Maternal mortality reported by others are, Kanwar et al. $12 \%$ and Siddiq et al $9.7 \% .^{27-30}$

\section{Other alternative techniques}

\section{Balloon tamponade for PPH}

The morbidity of the surgeries like obstetric hysterectomy and the desire to preserve fertility has led to the development of new therapies including balloon tamponade.

Over the last two decades, balloon tamponade use has been reported for the management of postpartum hemorrhage. Success rates for control of postpartum bleeding have ranged from 71 to $87 \% .31-32$ The principle of balloon tamponade therapy is to fill the uterine cavity to control bleeding with pressure.

Balloon tamponade is a readily available, inexpensive procedure that can be performed in the delivery room as a clinical tool to determine if additional more morbid therapies are required or as therapy for postpartum hemorrhage. The balloon catheters were inserted in the delivery room or in the operating room under epidural anesthesia or intravenous sedation.

The procedure was considered successful if bleeding stopped with balloon inflation. Balloon tamponade was continued as recommended for at least 24 hours. Balloons were deflated gradually over several hours while monitoring for uterine bleeding. Broad-spectrum antibiotics were administered until removal of the catheters.

\section{Brace sutures}

The invention of the B-Lynch brace suturing technique has proved invaluable in the control of massive postpartum haemorrhage. In 1997, B-Lynch pioneered 
the use of uterine compression sutures for postpartum hemorrhage. These compression sutures require laparotomy but are considered not as invasive as obstetric hysterectomy.

Two longitudinal sutures in B Lynch look like a "bracesuspender," and thus B-Lynch suture is sometimes referred to as the "brace suture." From 1989 to 1995, they used this suture for five women with PPH, all achieving complete hemostasis, which they described in the British Journal of Obstetrics and Gynaecology in 1997. ${ }^{33}$ Various other uterine compression sutures have been described, with the inventor's name being used, such as Hayman, Cho ,Pereira, Ouahba, or Hackethal suture. Although the success rate hitherto reported has been $76-100 \%$, there are no reliable data for this. ${ }^{34}$ There have been no reports of maternal mortality due to uterine compression sutures. Some complications have been reported including uterine necrosis, pyometra and uterine synechiae. Excluding the studies in which patients did not desire future pregnancy, the rate of future pregnancy was $11-75 \%$, with an average rate of $32 \%$.

\section{Internal iliac artery ligation}

Bilateral internal iliac arteries ligation is a highly effective method of stemming pelvic hemorrhage. Previously in sever PPH or in any other surgical procedure leading to postoperative bleeding, the traditional surgical treatment is to perform an emergency hysterectomy and eliminating possibility of future fertility. But IIAL is an alternative lifesaving operation which preserves the reproductive capacity. After the first report of hypogastric artery ligation (HAL) in 1960s as one of the surgical procedures to prevent hysterectomy, it has gained an important place in the armamentarium of conservative treatment of obstetrical haemorrhage. ${ }^{35}$ Bilateral internal iliac artery ligation (BIL) has been used in life threatening hemorrhagic conditions like placenta previa, postpartum hemorrhage, cervical and vaginal tear, cervical pregnancy, broad ligament haematoma and uterine rupture etc.

The main underlying principle in ligation of the internal iliac artery for control of pelvic hemorrhage is the conversion of an arterial pressure circulation into a venous pressure circulation. Iwata A. et al. reported that the success for IIAL was between $40 \%$ and $100 \%$ and it prevents hysterectomy by $50 \%$. IIAL is reported to be less successful in hysterectomy prevention in cases with uterine atony, when compared to other causes of $\mathrm{PPH}{ }^{36}$ In abnormal placentation, the traditional treatment has been hysterectomy. However, in the recent years, uterine conservative methods have been described.

\section{Selective arterial embolization}

In developed countries, UAE has been utilized as an alternative method for management of intractable bleeding following failure of medical management, and uterine artery pseudoaneurysm or arteriovenous malformation. 37Since the first report of the successful use of UAE for the treatment of postpartum hemorrhage in 1979, success rates have been infrequently reported. In one report, only five successful cases of UAE were reported over a period of 5 years, with the authors stating that patient transfer for UAE was challenging and that no exact data were available supporting predictors of successful outcomes. ${ }^{38}$

The UAE success rate in patients with severe hemorrhage (bleeding loss >1500 ml), DIC, and hemodynamic shock was $71.5 \%$, with hemodynamic shock representing a failure factor. ${ }^{39}$ In the study by Tae Hee Kim et al, the success rate of uterine artery embolization was $96 \% .{ }^{40}$ Optimal patient selection and the appropriate position of $\mathrm{UAE}$ in the treatment decision tree for PPH remain to be elucidated. However, despite a growing body of data attesting to the effectiveness of the procedure, it continues to be an underutilized procedure.

\section{CONCLUSION}

Obstetric hysterectomy has always been a nightmare scenario for most obstetricians. Because this procedure is an end of road measure, it is absolutely necessary to be hundred per cent sure and beyond any reasonable doubt that obstetric hysterectomy is the only answer. With the improvement in modern obstetrics and newer modalities of treatment for PPH and conservative management of morbidly adherent placenta the incidence of obstetric hysterectomy has reduced. However, it will never disappear completely from the practice of Obstetrics for a simple reason and that is we cannot guarantee that all these new techniques can be successful in all cases.

Funding: No funding sources

Conflict of interest: None declared

Ethical approval: Not required

\section{REFERENCES}

1. Blum J, Durocher J, Abbas D. Proposal for the inclusion of misoprostol in the WHO model list of essential medicines. Gynuity Health Projects. 2010:1-34.

2. Anita K, Kavita WW. Emergency obstetric hysterectomy. J Obstet Gyneco India 2005. 55(2):132-4.

3. Verma A, Soni A. Emergency Obstetric Hysterectomy-A Five Year Review. JK Sci. 2017;19(4).

4. Zelop CM, Harlow BL, Frigoletto FD, Safon LE, Saltzman DH. Emergency peripartum hysterectomy. Am J Obstet Gynecol. 1993;168(5):1443-8.

5. Najam R, Bansal P, Sharma R, Agrawal D. Emergency Obstetric Hysterectomy: A retrospective study at a tertiary care hospital. J Clinic Diagnos Res. 2010;4:2864-2868. 
6. Bhat S, Bhave S. Obstetric Hysterectomy a life saving procedure and its complication. Int $\mathrm{J}$ Med and Dent Sci. 2016;5(1):996-1001.

7. Sharma B, Saxena N, Gupta V. A retrospective study of emergency obstetric hysterectomy in a tertiary care center for a period of 5 years. Int $\mathrm{J}$ Reprod Contracept Obstet Gynecol. 2016;5(11):3778-81.

8. Sparić R1, Kadija S, Hudelist G, Glisić A, Buzadzić S. History of caesarean hysterectomy,Acta Chir Iugosl. 2012;59(1):9-12

9. Zorlu CG, Turan C, Isik AZ, Danisman N, Mungan $\mathrm{T}$, Gokmen O. Emergency hysterectomy in modern obstetric practice. Changing clinical perspective in time. Acta Obstet Gynaecol Scand. 1998;77(2):18690.

10. Shirodker SD, Pandey A, Yadav S. Emergency obstetric hysterectomy: review at a tertiary care hospital. Int J Reprod Contracept Obstet Gynecol. 2016;5(11):3811-4.

11. Gupta U, Anjana. Changing trends in emergency hysterectomy in obstetric practice in a large teaching hospital. J Obstet Gyneco India.1992;42(2):169-73.

12. Chestnut DH, Eden RD, Gall SA, Parker RT Peripartum hysterectomy: A review of cesarean and postpartum hysterectomy. Obstet Gynecol. 1985 65(3):365.

13. Barclay D, Hawks BL, Frueh DM, Power JD, Struble RH. Elective cesarean hysterectomy: a 5-year comparison with cesarean section. Am J Obstet Gynaecol. 1976;124(8):900-11.

14. Bhattacharyya R, Mukherjee K. Emergency peripartum hysterectomy : indications and obstetric outcome(a 5-year review), Int Educat Res J.2016;2(5):58-60

15. AbouZahr C. Antepartum and Postpartum Hemorrhage. In: Murray, L.J. and Boston, A., Eds., Health Dimen- sions of Sex and Reproduction, Harvard School of Public Health on Behalf of the World Health Organization and the World Bank, 1998;165-87.

16. Say L, Chou D, Gemmill A, Tunçalp Ö, Moller AB, Daniels J, et al. Global causes of maternal death: a WHO systematic analysis. Lancet Glob Health. 2014;2(6):e323-33.

17. Kant A, Wadhwani K. Emergency obstetric hysterectomy. J Obstet Gynecol India. 2005;55:1324.

18. Buetow MP. Sonography of placenta percreta during the first trimester. Am J Roentgenol. 2002;179(2):535.

19. Armstrong CA, Harding S, Matthews T, Dickinson JE. Is placenta accreta catching up with us? ANZJOG. 2004:77(3);210-31.

20. Kastner ES, Figueroa R, Garry D. Emergency peri partum hysterectomy: experience at a community teaching hospital. Obstet Gynaecol India. 2002; 99(6):971-5.

21. Praneshwari Devi RK, Singh NN, Singh D. Emergency obstetric hystrectomy. J Obstet Gynaecol India. 2004;54:343-5.
22. Parveen M, Manjeet K, Anju G. Peripartum hysterectomy-a five-year study. J Obstet Gynaecol India. 2008;58(6):504-06.

23. Ian Donald. Practical obstetric problems, BI publications Pvt Ltd, New Delhi $5^{\text {th }}$ ed, 795-804

24. Jayaram S, Varghese AP. A clinical review of obstetric hysterectomies done in medical college, Kottayam for a period of six years. Int J Reprod Contracept Obstet Gynecol. 2016;5(2):482-6.

25. Ambika HE, Swathi Bhat, Lepakshi BG, Savitha CS. A clinical review of emergency obstetric hysterectomy Indian J Obstet Gynecol Res. 2017;4(4):424-6

26. Clark SL, Yeh SY, Phelan JP, Bruce S, Paul RH. Emergency hysterectomy for obstetric haemorrhage. Obstet Gynecol. 1984;64(3):376-80.

27. Fatema K, Das SR, Alam IP, Parvin Z, Emergency Obstetric Hysterectomy: A Review of 40 cases in Faridpur Medical College Hospital Faridpur Med. Coll. J. 2016;11(1):1-5.

28. Nazma Bano Shaikh, Shabnam Shaikh, Jan Muhammad Shaikh. Morbidity and mortality associated with Obstetric hysterectomy. J Ayub Med Coll Abottabad. 2010;22(2):100-4.

29. Kanwar M, Sood PL, Gupta KB. Emergency hysterectomy in obstetrics. J Obstet Gynecol India. 2003;53:350-2.

30. Siddiq N, Ghazi A, Jabbar S, Ali T. Emergency Obstetrical Hysterectomy (EOH): A Life saving procedure in obstetrics. Pakistan J Surgery. 2007;23(3):217-9.

31. Seror J, Allouche C, Elhaik S. Use of SengstakenBlakemore tube in massive postpartum hemorrhage: a series of 17 cases. Acta Obstet Gynecol Scand. 2005;84(7):660-4.

32. Condous GS, Arulkumaran S, Symonds I, Chapman $\mathrm{R}$, Sinha A, Razvi K. The "tamponade test" in the management of massive postpartum hemorrhage. Obstet Gynecol. 2003;101(4):767-72

33. B-Lynch C, Coker A, Lawal AH, Abu J, Cowen MJ. The B-Lynch surgical technique for the control of massive postpartum haemorrhage: an alternative to hysterectomy? Five cases reported. Br J Obstet Gynaecol. 1997;104(3):372-5.

34. Hayman RG, Arulkumaran S, Steer PJ. Uterine compression sutures: surgical management of postpartum hemorrhage. Obstet Gynecol. 2002;99(3):502-6.

35. Sziller I, Hupuczi P, Papp Z. Hypogastric Artery Ligation for Severe Hemor-rhage in Obstetric Patients. J Perinatal Med.2007;35(3):187-92.

36. Iwata A, Murayama Y, Itakura A, Baba K, Seki H, Takeda S. Limitations of Internal Iliac Artery Ligation for the Reduction of Intraoperative Hemorrhage during Cesarean Hysterectomy in Cases of Placenta Previaaccreta. J Obstet Gynaecol Res.2010;36(2):254-9.

37. Isono W, Tsutsumi R, Wada-Hiraike O, Fujimoto A, Osuga Y, Yano $\mathrm{T}$, et al. Uterine artery pseudoaneurysm after cesarean section: case report 
and literature review. J Minim Invasive Gynecol. 2010;17(6):687-91.

38. Hansch E, Chitkara U, McAlpine J, El-Sayed Y, Dake MD, Razavi MK. Pelvic arterial embolization for control of obstetric hemorrhage: a five-year experience. Am J Obstet Gynecol. 1999;180(6):1454-60.

39. Touboul C, Badiou W, Saada J, Pelage JP, Payen D, Vicaut E, et al. Efficacy of selective arterial embolisation for the treatment of life-threatening post-partum haemorrhage in a large population. PLoS One. 2008;3(11):e3819.
40. Kim TH, Lee HH, Kim JM, Ryu AL, Chung SH, Lee WS. Uterine artery embolization for primary postpartum hemorrhage, Iran J Reprod Med. 2013;11(6):511-8.

Cite this article as: Tasneem F, Shanbhag V. Obstetric hysterectomy: a receding trend. Int J Reprod Contracept Obstet Gynecol 2019;8:353-8. 